\title{
BMJ Open Pain complaints after consecutive nights and quick returns in Norwegian nurses working three-shift rotation: an observational study
}

\author{
Maria Katsifaraki, ${ }^{1}$ Kristian Bernhard Nilsen, ${ }^{2}$ Jan Olav Christensen, ${ }^{1}$ \\ Morten Wærsted, ${ }^{1}$ Stein Knardahl, ${ }^{1}$ Bjørn Bjorvatn (D) , ${ }^{3,4}$ Mikko Härmä, ${ }^{5}$ \\ Dagfinn Matre (D) ${ }^{1}$
}

To cite: Katsifaraki M, Nilsen KB, Christensen J0, et al. Pain complaints after consecutive nights and quick returns in Norwegian nurses working three-shift rotation: an observational study. BMJ Open 2020;10:e035533. doi:10.1136/ bmjopen-2019-035533

- Prepublication history and additional material for this paper are available online. To view these files, please visit the journal online (http://dx.doi. org/10.1136/bmjopen-2019035533).

Received 05 November 2019 Revised 12 May 2020

Accepted 11 June 2020

Check for updates

(c) Author(s) (or their employer(s)) 2020. Re-use permitted under CC BY-NC. No commercial re-use. See rights and permissions. Published by BMJ.

For numbered affiliations see end of article.

Correspondence to

Dr Dagfinn Matre;

dagfinn.matre@stami.no

\section{ABSTRACT}

Objectives To determine whether nurses working consecutive night shifts, or short transitions between shifts (quick returns (QRs)), yielded higher risk for pain complaints when compared with regular morning shifts. Sleep duration was tested as a potential mediator.

Design Observational diary study.

Setting Random hospitals.

Participants Nurses with three-shift rotation (morning, evening and night), $n=679,22-63$ years old.

Outcomes measures Daily ratings of working hours, sleep and subjective pain complaints in six anatomical regions (head, neck/shoulder/upper back, upper extremity, low back, lower extremity and abdomen) for 28 days. In addition, we assessed demographics, habitual sleep and pain complaints, work and lifestyle factors. It was tested (1) whether the risk for pain complaints was higher after workday 3 versus after workday 2, and whether the difference was larger for consecutive night shifts versus consecutive morning shifts, and (2) whether the risk for pain complaints was higher after QRs versus after two morning shifts. Risk for pain complaints refers to combined increased risk for any pain and risk for increased intensity. Results Adjusted analyses showed no shift type by workday interaction for pain complaints in the neck/ shoulder/upper back, upper extremities, low back, lower extremities or abdomen. For headache, a strong trend indicated that the risk was higher on workday 3 compared with workday 2 for night shifts $(\mathrm{OR} 1.13,95 \% \mathrm{Cl} 0.99$ to 1.28). The risk was lowered if sleep duration was taken into account ( $\mathrm{OR} 0.37,95 \% \mathrm{Cl} 0.17$ to 0.81 ). No conclusive support was found for the risk for pain complaints being higher after QRs, compared with after morning shifts.

Conclusions For five of six pain complaints, the hypotheses were not supported by the current data. For headache, we found potential support for a sleep-relieving effect on headache after working several nights in a row. Pain complaints were not instigated or exacerbated by an evening-to-morning transition between shifts.

\section{INTRODUCTION}

Shift work is a broad term covering different aspects of non-daytime work. In nursing, a common example is working on a rotating

\section{Strengths and limitations of this study}

- The first study to assess the association between daily variations in working hours and pain complaints.

- Daily reports on pain complaints reduce recall bias, electronic time stamp documented time of assessment.

- Participants are from many hospitals, increasing external validity, whereas the relatively low response rate may reduce external validity.

- The majority of the nurses do not report pain complaints, which limits statistical power.

three-shift schedule, alternating among morning, evening and night shifts. A common aspect of rotating shift work is working consecutive night shifts. Compared with working single nights, consecutive night shifts may increase the risk of developing cumulative sleep loss. ${ }^{12}$

Another common characteristic of rotating shift work is quick returns (QRs), typically referring to the rest period between two consecutive shifts being 11 hours or less. ${ }^{3}$ QRs may increase the risk for transient sleep loss, most commonly after an evening-to-morning shift transition. ${ }^{4-6}$ Although workers have the opportunity to sleep at night during an evening-to-morning $\mathrm{QR}$, they risk incurring a sleep debt since time between shifts includes time for commuting and social activities as well.

Short sleep duration is a potential contributing factor in musculoskeletal ${ }^{7-9}$ and gastrointestinal pain complaints. ${ }^{10-12}$ Hence, it is plausible that occupational exposures associated with increased risk of sleep loss are also associated with increased risk of musculoskeletal and gastrointestinal pain complaints. A previous study from our group found that 
short sleep duration partially mediated effects of night shifts on pain complaints in nurses working a rotating three-shift schedule. ${ }^{13}$ In the present study, we analysed a subset of the same data in order to determine whether working consecutive night shifts was more negative than working the same number of consecutive morning shifts. In the subset, subjects were required to have the first day off followed by two or three consecutive morning or night shifts. To our knowledge, the present diary study is the first to assess the association between daily variations in working hours and pain complaints. A similar design has previously been used in pain patients. ${ }^{1415}$

We also determined whether an evening-to-morning transition was more detrimental than a morning-tomorning transition. To our knowledge, there are no earlier studies exploring the association between QRs and pain. A second subset of the same data was analysed, including subjects with two consecutive morning shifts and subjects with an evening-to-morning transition.

Two hypotheses were tested. (1) The risk for pain complaints increases over the course of consecutive workdays, and the increase is larger for consecutive night shifts, compared with consecutive morning shifts. (2) The risk for pain complaints is higher after $\mathrm{QR}$ versus after two morning shifts. Subsidiary hypotheses were that sleep duration partially mediated these potential associations. Risk for pain complaints refers to combined increased risk for any pain (if no pain is present) and risk for increased intensity (if pain is present). We are not aware of any earlier studies on this topic.

\section{METHOD}

\section{Subjects}

We recruited a sample of nurses working at hospitals across Norway, by sending an invitation by either postal mail $(\mathrm{n}=2$ $000)$ or email $(n=20500)$ to randomly selected members of the Norwegian Nurses Organisation. The invitation stated that the study's aim was to determine associations between shift work, sleep and health complaints, and to map risk factors for developing health complaints. Inclusion criteria were working as a nurse, working in more than $50 \%$ position, having a shift schedule that included night work, being between 18 and 63 years old, not being pregnant, not breast-feeding, and not on sick leave for more than 2 weeks during the last 6 months. Correcting for the inclusion criteria, the number of eligible nurses receiving the invitation was estimated to be approximately 5400. Of these, 4001 nurses asked for a login key and were thus interested in participating. In total, 1032 subjects completed the Baseline Questionnaire. Of these, 679 nurses (66\%) answered a follow-up Diary Questionnaire for 28 consecutive days.

\section{Patient and public involvement}

The Norwegian Nurses Organisation was consulted before designing the questionnaires, and was allowed to come with feedback that were taken into consideration by the research team. The organisation was also informed first hand, about new publications based on the data.

\section{Data collection and procedure}

Working hours, sleep and subjective pain complaints were rated daily electronically on smartphone. An SMS (short message service) text message (email if not owning a smartphone) was sent each night at 21:00 in order to remind the participants to fill out the Diary Questionnaire. The diary opened by clicking a web address in the message body. We instructed the participants to respond to the questionnaire as soon as possible after receiving the SMS, after which the data were sent via the internet to a secure server at the research institute. Of 16250 responses received, 8775 (54\%) were received within 1 hour and $11537(71 \%)$ within 2 hours. The diary time variables were entered in a 24-hour time format via pulldown menus, one for hour $(0,1,2, \ldots, 23)$ and one for minute $(0,5,10, \ldots, 55)$. For ordinal and yes/no variables, subjects were allowed to select only one from a default set of mutually exclusive responses. Data collection started in October 2014 and ended in November 2015.

\section{Measures}

Diary Questionnaire

Working hours: Participants indicated whether they had been working within the previous 24 hours, as well as the start and end times of that shift, or if they had been off work or sick that day. Shift type was categorised into three categories by shift starting time: morning shift (starting time 05:00-12:00), evening shift (starting time 12:0118:00) and night shift (starting time 18:01-04:59).

Sleep questions were derived from the Consensus Sleep Diary. ${ }^{16}$ Participants were asked the following information related to their main sleep:

'What time did you get into bed?', 'What time did you try to fall asleep?', 'How long in hours and minutes did it take you to fall asleep? (sleep-onset latency, SOL), 'How many times did you wake up, not counting your final awakening?', 'In total, how long did these awakenings last?' (awake hour/minute; wake after sleep onset, WASO), 'What time was your final awakening?' and 'What time did you get out of bed after your main sleep?' (get up hour/minute; time awake prior to rising), 'Did you wake up earlier than planned?'. To account for napping, the final question was: 'How long did you sleep in addition to your main sleep during the past 24 hours?' All time variables were converted from hh:mm format to decimal format. Inconsistent data entries were manually cleaned.

Total sleep time (TST) of the main sleep was calculated by subtracting SOL and WASO from the difference between the time trying to sleep and the time of final awakening. Sleep duration was calculated by adding TST and napping.

Pain complaints during the previous 24 hours were rated on a Likert-type Scale with categories 0 (not troubled by pain), 1 (a little troubled by pain), 2 (somewhat troubled by pain) and 3 (very troubled by pain). 
Complaints were rated for six regions: head, neck/ shoulder/upper back, upper extremities (arm, wrist and hand), low back, lower extremities (hip, knee, leg and foot), and abdomen.

Use of medication to fall asleep was measured by a single item (yes/no), and was treated as a control variable in the analyses.

\section{Baseline Questionnaire}

Subjects answered a web-based Baseline Questionnaire before the diary commenced, assessing several lifestyle and work-related variables, including selected factors from the General Nordic Questionnaire for Psychosocial and Social Factors at Work. ${ }^{17}$ In addition, a Pain Complaint Severity Index (score range 0-9) pertaining to the last month was assessed by a questionnaire by Steingrímsdóttir et al, ${ }^{18}$ chronotype was assessed by seven items from the Horne-Østberg MorningnessEveningess Questionnaire, ${ }^{19}$ sleep problems and sleepiness was assessed by the Bergen Insomnia $\mathrm{Scale}^{20}$ and by the Epworth Sleepiness Scale. ${ }^{21}$ The mentioned variables were adjusted for in all analyses, since they potentially affect both the independent and dependent variables. Selection of these potential adjustment variables has been presented in detail elsewhere. ${ }^{22}$

\section{Data processing}

Working more than three consecutive nights is not very common in a rotating schedule in Norway. Thus, the number of consecutive shifts included in the analysis was restricted to three. Hypothesis 1 assumed that pain risk would increase from workday 2 to workday 3 , and that this increase would be larger if the workdays were night shifts than morning shifts. Thus, we were looking for a workday by shift-type interaction for each pain region. We required that participants had at least 1 day off before starting on the two or three consecutive shifts. Of the 679 participants, 309 worked two consecutive morning shifts at least once during the 28 days. Among these, 162 participants worked three consecutive morning shifts. This constituted the 'consecutive morning shift group' (figure 1A and table 1). The 'consecutive night shift group' was determined in the same manner, the corresponding numbers being 278 participants with two night shifts and 141 participants
A

Morning
\begin{tabular}{|c|c|c|c|c|}
\hline $\mathbf{X}$ & $\mathbf{M}$ & $\mathbf{M}$ & $\mathbf{M}$ & \\
\hline $\mathbf{0}$ & $\mathbf{1}$ & $\mathbf{2}$ & $\mathbf{3}$ & \\
\hline
\end{tabular}

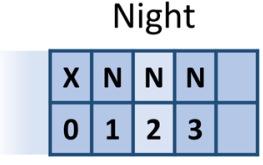

B

Morning
\begin{tabular}{|l|l|l|l|}
\hline $\mathbf{X}$ & $\mathbf{M}$ & $\mathrm{M}$ & \\
\hline $\mathbf{0}$ & $\mathbf{1}$ & $\mathbf{2}$ & \\
\hline
\end{tabular}

Quick return

\begin{tabular}{|l|l|l|l|}
\hline$X$ & $E$ & $M$ & \\
\hline 0 & 1 & 2 & \\
\hline
\end{tabular}

$X=$ day off $M=$ morning $\mathrm{E}=$ evening $\mathrm{N}=$ night $0-3=$ workday
Figure 1 Work schedules by subgroups. (A) Consecutive morning and night shift groups. (B) Consecutive morning group and quick return group. with three night shifts. The same subject could have several repeated instances of 1 day off and two or three consecutive shifts in the 28-day data collection period. A priori power calculations assuming $80 \%$ power indicated that a sample size of 100 was sufficient to detect a $20 \%$ difference in pain complaints, if pain complaints were treated as a continuous variable.

Hypothesis 2 assumed that pain risk would be higher after an evening-to-morning transition than after a morning-to-morning transition. The 'QR group' (176 participants) was comprised by participants having 1 day off followed by an evening-to-morning transition (figure 1B and table 1). This group was compared with the group of 309 participants that worked two consecutive morning shifts. Group comparisons were made of pain complaints at workday 2.

\section{Statistical analysis}

Sleep durations for the 'consecutive morning shift group' versus the 'consecutive night shift group' and the 'QR group' versus the 'consecutive morning shift group' were normally distributed and compared by linear mixed models analyses, adjusted for age, insomnia and sleep medication. The sleep duration datasets consisted of both paired and unpaired observations, $122(44 \%)$ of the 278 subjects in the night shift group (table 1) were also in the morning shift group (paired observations), while the remaining 156 (56\%) only were in the night shift condition (unpaired observations). For the QR comparison, the corresponding percentages were $42 \%$ (paired) and 58\% (unpaired). Despite an unbalanced dataset, data from both paired and unpaired observations were included since complete case analysis is generally assumed to reduce the robustness of the estimates. ${ }^{23}$ Cohen's d was calculated as effect size measurement for sleep duration.

The pain data were analysed with a regression-based approach that takes into account the measurement level of the outcome variables (ordered categorical), as well as the clustering of outcome variables within individuals due to repeated observations (handled by random effects). Due to its flexibility, Stata's (Stata V.16, StataCorp LLC, Texas, USA) structural equation modelling approach was chosen. Since the response variable was ordinal, generalised structural equation modelling was applied, with maximum likelihood estimation. This approach tests all paths in the conceptual model (figure 2) separately with regression. In addition, it decomposes the total effect $(\mathrm{X} \rightarrow \mathrm{Y})$ into direct (path c) and indirect (path a and b) effects. An assumption with ordinal regression is that the odds across each level of the ordinal variable is stable. This is called the assumption of proportional odds and was tested for all pain outcome models by use of the omodel and brant tests in Stata. A significant result indicated that the assumption had been violated. If that was the case, the dependent variable was dichotomised and a logistic regression was run instead. 
Table 1 Descriptive statistics on pain complaint frequency for each pain region, by shift type (morning, night and quick returns) and workday (1-3)

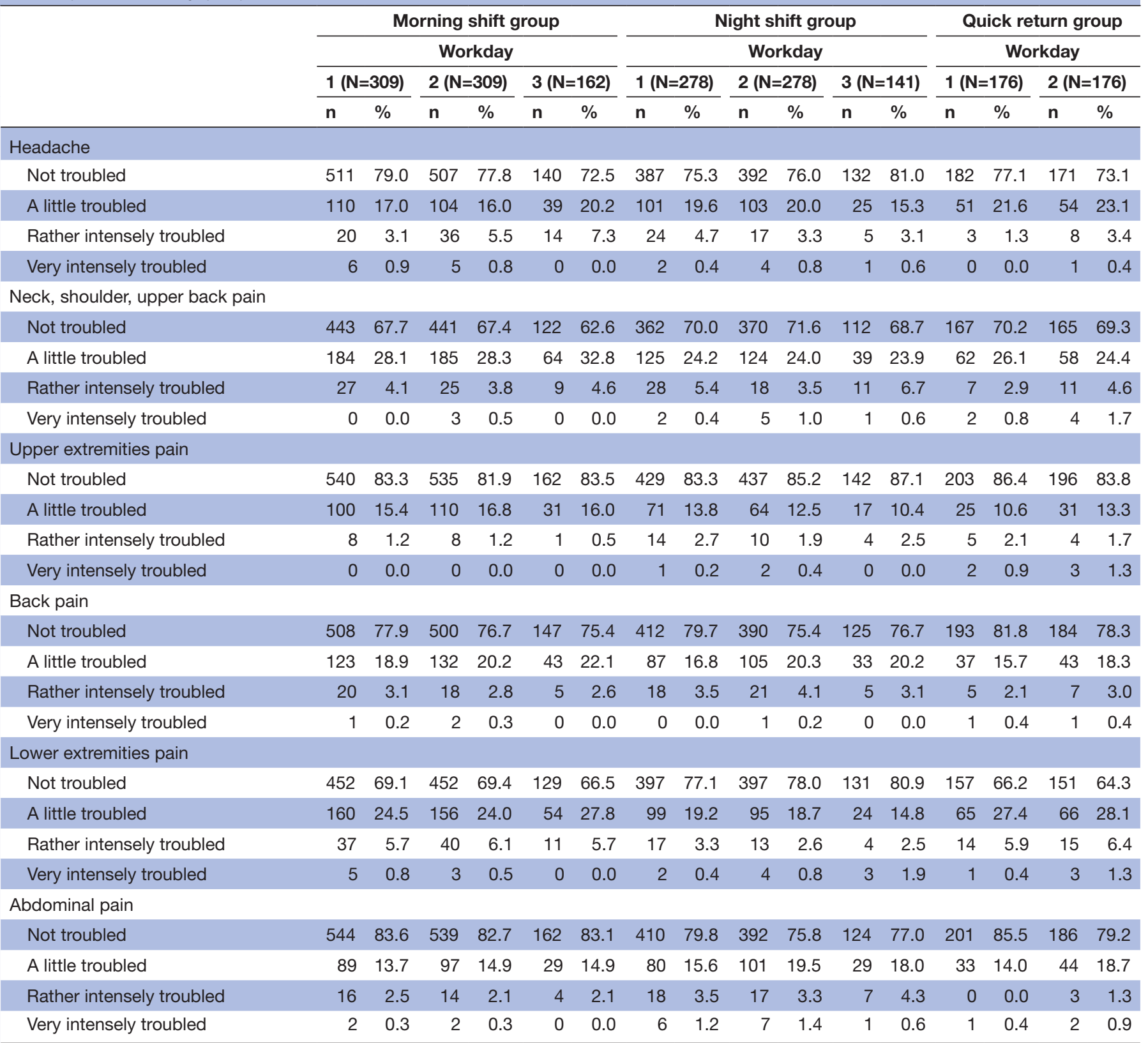

$\mathrm{N}$, Number of participants; $n$, number of observations.

First, it was established whether the independent variable was associated with pain complaints (ordinal variable) (path c, figure 2A). When testing hypothesis 1 , independent variables were shift type (morning vs night), workday (workday 2 vs workday 3 ) and the shift type by workday interaction (our main interest). The analysis was repeated for the six pain regions. When testing hypothesis 2 , the independent variable was shift-type transition (morning-morning vs evening-morning). Using ordered categorical pain complaints as the dependent variable, results refer to combined pain prevalence (scores changing from 0 to 1 ) and intensity (scores changing from 1 to 2 , or from 2 to 3 ). The proportion of missing data was generally very low. For the pain outcomes, missing data varied from $0 \%$ to $0.9 \%$ and for the covariates, missing data varied from $0 \%$ to $1.5 \%$. Missing data were deleted listwise.

It was then tested whether the exposure variable was associated with the mediator variable (continuous sleep duration, path a) and whether the mediator variable was associated with the outcome variable, after controlling for the exposure variable (path b). The fourth step established whether the mediator variable mediated the relationship between the exposure variable and the outcome variable (figure 2B, path $\mathrm{c}^{\prime}$ ). We decided to discontinue the analysis if the significance level of path c was far from 0.05 . The results are presented as ORs. 
A

$x$

c

B

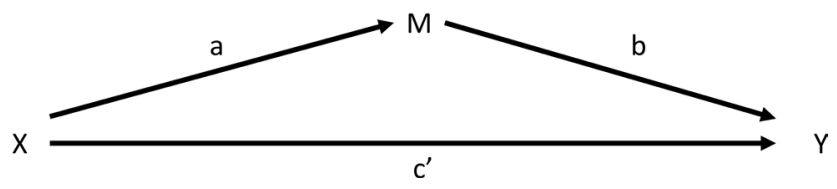

Figure 2 (A) X: Independent variable=shift type, $Y$ : Dependent variable $=$ pain, path $c(X \rightarrow Y)$ indicates that the independent variable is associated with the dependent variable. (B) Mediation model. X: Independent variable, Y: Dependent variable, $\mathrm{M}$ : Mediator (sleep duration), path a $(X \rightarrow M)$ : Independent variable is associated with the mediator, path $b(\mathrm{M} \rightarrow \mathrm{Y})$ : Mediator is associated with the dependent variable, path $c^{\prime}(X \rightarrow Y)$ : Independent variable is associated with the dependent variable, while controlling for $\mathrm{M}$.

\section{RESULTS}

Online supplementary table S1 lists demographic and work-related characteristics. The majority of the nurses in the study were female $(90.6 \%)$ and the mean age was 41 years $(\mathrm{SD}=11.1)$.

\section{Pain complaints and sleep duration}

Table 1 shows pain complaint frequencies across pain regions and workdays. A majority of the nurses reported that they were 'not troubled' by any pain complaints.

Table 2 shows differences in sleep duration, including statistical comparisons between shift groups (across workdays) and between workdays (within shift groups). Between shifts, daytime sleep after night shifts was shorter than nocturnal sleep after morning shifts (Cohen's $\mathrm{d}=0.49$ ). From workday 2 to workday 3, sleep duration after morning shifts did not differ (Cohen's d=-0.08), whereas for night shifts, sleep duration was shorter after workday 3 versus after workday 2 (Cohen's d=0.27). Sleep duration was also shorter the night between the eveningto-morning transition than the night between the morning-to-morning transition (Cohen's d=0.36) table 2.

\section{Consecutive shifts and pain}

Adjusted analyses showed no shift type by workday interaction for pain complaints in the neck/shoulder/upper back, upper extremities, low back, lower extremities or abdomen. For headache, a strong trend indicated that the difference in pain complaints between workdays 2 and 3 was associated with shift type (adjusted OR $0.50,95 \%$ CI 0.25 to 1.02 $(\mathrm{p}=0.055)$, table 3$)$. An OR less than 1 indicated that the combined effect of night shifts (vs morning shifts) and workday 3 (vs workday 2) was associated with a lower risk for headache. Analysing the direct effect separately (path c') indicated a weak detrimental effect of going from workday 2 to workday 3 for night shifts if sleep was not taken into account (OR 1.13, 95\% CI 0.99 to 1.28). However, analysing the indirect effect indicated that taking sleep duration into account was associated with a lower risk for headache (OR $0.37,95 \%$ CI 0.17 to 0.81 ).

Concerning main effects, night shifts, compared with morning shifts, were associated with lower levels of lower extremity pain (OR $0.39,95 \%$ CI 0.22 to 0.69 ), and higher levels of low back pain (OR 1.73, $95 \%$ CI 1.02 to 2.92) and abdominal pain (OR 3.17, 95\% CI 1.80 to 5.60). There was also a tendency towards higher neck pain after workday 3 versus workday 2 (OR 1.52, 95\% CI 0.54 to 1.32). The analyses were also run without the interaction term, since coefficients due to main effects may be difficult to interpret with the interaction term included (online supplementary table S2).

\section{QRs and pain}

An evening-to-morning $\mathrm{QR}$ tended to be associated with a lower risk for upper-extremity pain, compared with after two consecutive morning shifts (OR 0.56 , 95\% CI 0.29 to $1.09, \mathrm{p}=0.089$, table 4 ). For the remaining pain outcomes, adjusted analyses showed that pain complaints on workday 2 were not associated with schedule, ie, whether the nurse had worked an evening-to-morning QR or two consecutive morning shifts (table 4 ).

\section{DISCUSSION}

The present findings support the notion that five of six pain outcomes did not change over the course of

Table 2 Differences in sleep duration by shift type and workdays

\begin{tabular}{|c|c|c|c|c|c|c|c|c|c|c|}
\hline \multirow[b]{2}{*}{ Shift type } & \multirow[b]{2}{*}{ Workday } & \multicolumn{2}{|c|}{ Sleep duration } & \multirow{2}{*}{$\begin{array}{l}\text { Sleep } \\
\text { Timing }\end{array}$} & \multicolumn{3}{|c|}{ Between shifts* } & \multicolumn{3}{|c|}{ Between workdays $†$} \\
\hline & & Mean (hours) & $95 \% \mathrm{Cl}$ & & $\mathbf{z}$ & $P$ value & Cohen's d & $\mathbf{z}$ & $P$ value & Cohen's d \\
\hline Morning & 2 & 6.1 & 6.0 to 6.2 & Nocturnal & \multicolumn{2}{|c|}{ (ref) } & & \multicolumn{3}{|c|}{ (ref) } \\
\hline Night & 2 & 5.4 & 5.2 to 5.6 & Daytime & \multirow{2}{*}{-11.2} & \multirow{2}{*}{$<0.0001$} & \multirow{2}{*}{0.49} & \multicolumn{3}{|c|}{ (ref) } \\
\hline Night & 3 & 4.8 & 4.4 to 5.2 & Daytime & & & & -3.7 & $<0.0001$ & 0.27 \\
\hline
\end{tabular}

z, p: linear mixed models analysis, adjusted for age, insomnia and sleep medication.

*Model formula between shifts (morning vs night or morning vs QR): sleep_duration = shift_group + age + insomnia + medication, and between workdays.

†Sleep_duration = workday + age + insomnia + medication. Cohen's d: difference in means/pooled SD. 
Table 3 Separate unadjusted and adjusted analyses testing the effect of shift type, workday and its interaction on six different pain regions as dependent variables

\begin{tabular}{|c|c|c|c|c|c|c|}
\hline & & Unadjusted a & & & Adjusted a & \\
\hline & OR & $95 \% \mathrm{Cl}$ & $P$ value & OR & $95 \% \mathrm{Cl}$ & $P$ value \\
\hline Headache & & & & & & \\
\hline Shift type (night vs morning) & 1.02 & 0.67 to 1.54 & 0.944 & 1.02 & 0.67 to 1.54 & 0.942 \\
\hline Workday (3 vs 2) & 1.42 & 0.9 to 2.22 & 0.128 & 1.46 & 0.93 to 2.29 & 0.103 \\
\hline Shift typexworkday & 0.5 & 0.25 to 1.02 & 0.056 & 0.5 & 0.25 to 1.02 & 0.055 \\
\hline Neck, shoulder and upper back & & & & & & \\
\hline Shift type (night vs morning) & 0.84 & 0.54 to 1.32 & 0.458 & 0.84 & 0.54 to 1.32 & 0.449 \\
\hline Workday (3 vs 2) & 1.36 & 0.86 to 2.16 & 0.194 & 1.52 & 0.54 to 1.32 & 0.076 \\
\hline Shift typexworkday & 1.04 & 0.52 to 2.09 & 0.912 & 0.96 & 0.47 to 1.94 & 0.907 \\
\hline Upper extremity pain* & & & & & & \\
\hline Shift type (night vs morning) & 0.79 & 0.58 to 1.08 & 0.139 & 0.83 & 0.58 to 1.18 & 0.294 \\
\hline Workday (3 vs 2) & 0.9 & 0.58 to 1.37 & 0.614 & 0.87 & 0.54 to 1.38 & 0.546 \\
\hline Shift typexworkday & 0.95 & 0.48 to 1.86 & 0.88 & 0.92 & 0.43 to 1.97 & 0.835 \\
\hline Low back pain & & & & & & \\
\hline Shift type (night vs morning) & 1.4 & 0.83 to 2.34 & 0.205 & 1.73 & 1.02 to 2.92 & 0.042 \\
\hline Workday (3 vs 2) & 1.06 & 0.61 to 1.84 & 0.836 & 1.1 & 0.63 to 1.95 & 0.734 \\
\hline Shift typexworkday & 0.73 & 0.32 to 1.7 & 0.467 & 0.75 & 0.32 to 1.76 & 0.511 \\
\hline Lower extremity pain & & & & & & \\
\hline Shift type (night vs morning) & 0.35 & 0.2 to 0.61 & $<0.001$ & 0.39 & 0.22 to 0.69 & 0.001 \\
\hline Workday (3 vs 2) & 0.9 & 0.54 to 1.53 & 0.708 & 0.91 & 0.54 to 1.54 & 0.719 \\
\hline Shift typexworkday & 1.1 & 0.47 to 2.6 & 0.826 & 1.09 & 0.46 to 2.59 & 0.851 \\
\hline Abdominal pain & & & & & & \\
\hline Shift type (night vs morning) & 3.59 & 2.11 to 6.13 & $<0.001$ & 3.17 & 1.8 to 5.6 & $<0.001$ \\
\hline Workday (3 vs 2) & 0.99 & 0.55 to 1.79 & 0.984 & 0.99 & 0.54 to 1.84 & 0.984 \\
\hline Shift typexworkday & 1.33 & 0.58 to 3.03 & 0.501 & 1.27 & 0.54 to 3.02 & 0.583 \\
\hline
\end{tabular}

Adjustment variables: age, use of medication to sleep, work and lifestyle factors, baseline sleep problems and baseline pain.

*Dependent variable was dichotomised, due violation of the proportional odds assumption. Model formula (for headache as outcome variable) for unadjusted analyses.

†Headache $=$ group $x$ day, and for adjusted analyses.

†Headache $=$ group $x w o r k d a y+$ age + medication + job_demands + relaxed_org_climate + insomnia +habitual_headache.

consecutive workdays or depended on shift type. For headache, we found potential support for a sleep-relieving effect on headache after working several nights in a row. There was no conclusive support for the second hypothesis, that the risk of pain complaints is elevated after $\mathrm{QR}$, since pain complaints were not more severe after $\mathrm{QR}$ than after morning shifts.

A few secondary findings deserve mentioning. Sleep loss seemed to accumulate from workday 2 to workday 3 following night shifts. Sleep duration was also shorter

Table 4 Separate unadjusted and adjusted analyses testing the effect of quick returns versus morning shifts on six different pain regions as dependent variables

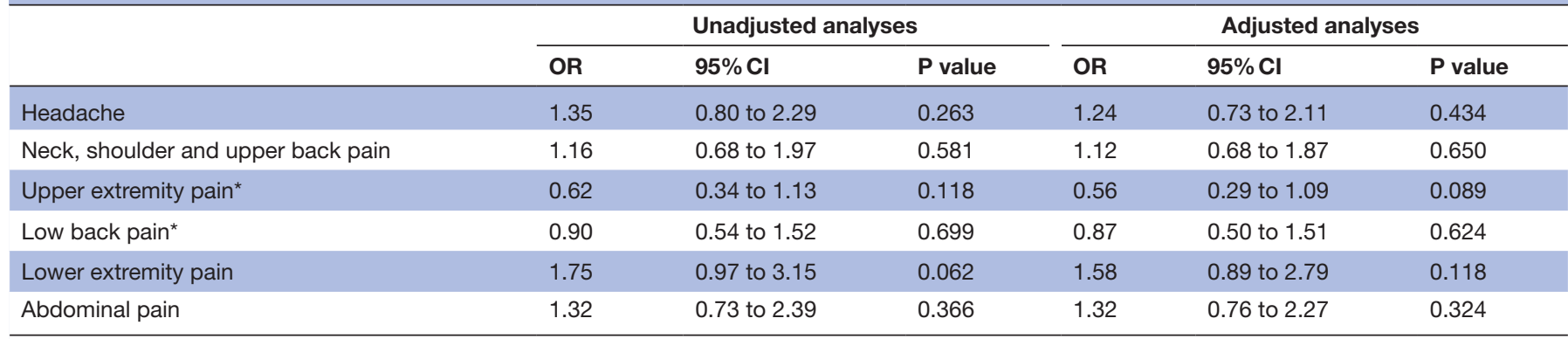

Analyses were adjusted for use of medication to sleep, age, work and lifestyle factors, baseline sleep problems and baseline pain.

${ }^{*}$ Dependent variable was dichotomised, due violation of the proportional odds assumption. 
after night shifts in general and after QR, compared with after morning shifts. Furthermore, night shifts were in general associated with increased risk for pain complaints in the lower back and abdomen (vs morning shifts), but reduced risk for lower extremity pain.

Several studies have reported that shift work or night shift is associated with pain, ${ }^{24-30}$ although contradicting studies also exist. ${ }^{31}{ }^{32}$ In cross-sectional and longitudinal studies, participants are typically asked about their pain complaints retrospectively for a week, month or year (eg, 'please rate the pain that you experienced during the previous week/month/year'). Recall bias is a known limitation in such study designs. Another issue, that may affect the results, is that pain complaints may exhibit quite large day-to-day variation. ${ }^{18}$ The present study asked participants to rate their pain daily across a 28-day period. By this 'naturalistic design', we aimed to determine whether presumably challenging shift schedules were followed by new pain complaints or elevation of existing pain complaints.

There seems to be support for a higher risk for headache after three night shifts than after three morning shifts, although the association was borderline significant $(\mathrm{p}=0.055)$. Still, looking further into the direct and indirect effects indicate that longer sleep duration may protect against the effect of consecutive night shifts. Previous findings indicated that sleep duration did not mediate the association between shift work and headache when consecutive days were not in the model. ${ }^{13}$ The present results may indicate that headache needs to accumulate over a few days in order to be relieved by sleep. The positive association between shift work and headache was not explained by sleep length in a recent prospective Danish study, ${ }^{33}$ despite that insomnia disorder was found to have a long-term effect on headache in a prospective Norwegian study. ${ }^{34}$ Further investigations into the association between night shift, sleep and headache are needed. For the remaining five pain outcomes, our results indicate that three repetitions of night shifts were not more detrimental than three repetitions of morning shifts. In a previous study based on the same material, we found that night work increased the risk of reporting headache, upper extremity pain and abdominal pain. ${ }^{13}$ That study did not distinguish between pain ratings following a single night shift and pain ratings following several night shifts in a row. For the present study, we hypothesised that pain complaints would exacerbate if the nurses worked several night shifts in a row, compared with several morning shifts. Except for on headache, this hypothesis was not supported. One explanation may be that the level of pain in general was low. If there is less variance in pain, the associations to work shifts will also be weaker. Another explanation may be that the number of subsequent shifts was limited to three, rendering the exposure dose (consecutive nights) too small. The nurses working several consecutive night shifts in the population could also be selected or habituated to this schedule; healthy workers coping well with this type of exposure. Another explanation for why several subsequent night shifts was not necessarily worse than one single night, ${ }^{13}$ may be related to findings that neurobehavioural impairment on the first night shift is often greater than on subsequent night shifts, due to extended wakefulness. ${ }^{35}$

QRs was not associated with pain complaints in the present group of nurses, indicating that an evening-to-morning transition was not more detrimental than two consecutive morning shifts. QRs in rotating shift work has been found to reduce sleep duration and was associated with more health complaints than not working QRs. ${ }^{36}$ Investigating sleep following various shift transitions (QRs, two consecutive night shifts, evening or day shifts), no transition encumbered as many detriments as QRs, which included short sleep duration (5.6hours), prolonged SOL and increased sleepiness. ${ }^{5}$ Although the mean sleep duration associated with $Q R$ in the present data (5.5hours) was basically identical to that reported by Vedaa et al, the 0.61 hour shortening of sleep compared with morning shifts was apparently not sufficient to affect the nurses' pain complaints. To our knowledge, there is a paucity of studies exploring the association between QRs and pain. One study found that less than 10hours off between shifts increased the risk of developing musculoskeletal complaints in the neck, shoulder and back. ${ }^{37} \mathrm{~A}$ recent cross-sectional study on nurses found that QRs the previous year were positively associated with number of pain sites. ${ }^{31}$ These studies were not diary studies. So, our finding that QRs did not seem to influence next day's pain can be regarded as a novel finding.

Daytime sleep after night shifts was 0.9 hours shorter than nocturnal sleep after morning shifts. A night shift-induced increase in headache and upper-extremity pain, as found by Katsifaraki $e t a l^{13}$ was not found. A possible explanation for the latter, could be that headache and upper-extremity pain result from single, rather than consecutive, night shifts. Workers typically experiencing these pain complaints may be less likely to work several night shifts in a row ('healthy worker effect'). Night shifts were in general associated with reduced pain in the lower extremities. This somewhat surprising finding could be linked to the activity level during night shifts, which is significantly lower than on a morning shift.

Some strengths and limitations should to be mentioned. Presumably, a diary study design reduces recall bias, since subjects are asked to recall pain only from the previous 24 hours. Also, given that the diary was electronic, a time stamp documented the time of the pain assessment. A limitation of the current study was a relatively low response rate, potentially introducing selection bias and limiting external validity. Another limitation was that, despite the 679 nurses answering the Diary Questionnaire, less than half worked the shift patterns needed for the present two hypotheses, reducing statistical power. The participants' socioeconomic status, however, can probably be regarded as homogeneous and the age range covered the full spectrum of work life. Finally, we cannot exclude the 
possibility that alcohol or sleep medication acted as a proxy for pain, although the diary explicitly asked about medication to sleep.

In conclusion, in this sample of nurses, working three consecutive night shifts was potentially associated with elevated risk of headache that could be relieved by sleep. For the remaining five pain complaints, working three consecutive night shifts was not associated with elevated complaint risk, compared with working three consecutive morning shifts. Moreover, working eveningto-morning transitions between shifts did not instigate or exacerbate pain complaints compared with working two consecutive morning shifts.

\section{Author affiliations}

${ }^{1}$ National Institute of Occupational Health, 0slo, Norway

${ }^{2}$ Department of Neurology, Oslo University Hospital, Ullevaal, Oslo, Norway ${ }^{3}$ Department of Global Public Health and Primary Care, University of Bergen, Bergen, Norway

${ }^{4}$ Norwegian Competence Center for Sleep Disorders, Haukeland University Hospital, Bergen, Norway

${ }^{5}$ Finnish Institute of Occupational Health, Helsinki, Finland

Acknowledgements The authors kindly acknowledge the nurses who faithfully have filled out the 28-day sleep and pain diary. We also kindly acknowledge Tiril Schjølberg, Daniel Pitz Jacobsen, Tonje Sirén Gjulem, Heidi Notø and Therese Tjensvoll Carlsen for participating in data collection and preparation.

Contributors DM, SK, KBN, BB, MW and MH contributed to the design of the study. DM and MK contributed to data collection, DM, JOC, MW, KBN and MK contributed to data analysis. MK and DM drafted the paper. All authors approved the final version.

Funding $\mathrm{BB}$ and $\mathrm{MH}$ were supported by NordForsk, Nordic Programme on Health and Welfare (74809).

Competing interests None declared.

Patient consent for publication Not required.

Ethics approval Ethical approval was obtained from the Norwegian Regional Committee for Medical Research Ethics (approval number 2012/199).

Provenance and peer review Not commissioned; externally peer reviewed.

Data availability statement Data are available upon reasonable request.

Open access This is an open access article distributed in accordance with the Creative Commons Attribution Non Commercial (CC BY-NC 4.0) license, which permits others to distribute, remix, adapt, build upon this work non-commercially, and license their derivative works on different terms, provided the original work is properly cited, appropriate credit is given, any changes made indicated, and the use is non-commercial. See: http://creativecommons.org/licenses/by-nc/4.0/.

ORCID iDs

Bjørn Bjorvatn http://orcid.org/0000-0001-7051-745X

Dagfinn Matre http://orcid.org/0000-0003-0042-6389

\section{REFERENCES}

1 Åkerstedt T. Shift work and disturbed sleep/wakefulness. Occup Med 2003;53:89-94

2 Sallinen M, Kecklund G. Shift work, sleep, and sleepiness differences between shift schedules and systems. Scand J Work Environ Health 2010;36:121-33.

3 European Parliament CotEU. Directive 2003/88/EC of the European parliament and of the council of 4 november 2003 concerning certain aspects of the organisation of working time, 2003. Available: https://eur-lex.europa.eu/legal-content/EN/ TXT/?uri=CELEX:32003L0088

4 Axelsson J, Åkerstedt T, Kecklund G, et al. Tolerance to shift workhow does it relate to sleep and wakefulness? Int Arch Occup Environ Health 2004;77:121-9.
5 Vedaa Øystein, Mørland E, Larsen M, et al. Sleep detriments associated with quick returns in rotating shift work: a diary study. $J$ Occup Environ Med 2017;59:522-7.

6 Costa G, Anelli MM, Castellini G, et al. Stress and sleep in nurses employed in " $3 \times 8$ " and " $2 \times 12$ " fast rotating shift schedules. Chronobiol Int 2014;31:1169-78.

7 Dzierzewski JM, Williams JM, Roditi D, et al. Daily variations in objective nighttime sleep and subjective morning pain in older adults with insomnia: evidence of covariation over time. J Am Geriatr Soc 2010;58:925-30.

8 Edwards RR, Almeida DM, Klick B, et al. Duration of sleep contributes to next-day pain report in the general population. Pain 2008;137:202-7.

9 Roehrs TA, Harris E, Randall S, et al. Pain sensitivity and recovery from mild chronic sleep loss. Sleep 2012;35:1667-72.

10 Huntley ED, Campo JV, Dahl RE, et al. Sleep characteristics of youth with functional abdominal pain and a healthy comparison group. $J$ Pediatr Psychol 2007;32:938-49.

11 Keefer L, Stepanski EJ, Ranjbaran Z, et al. An initial report of sleep disturbance in inactive inflammatory bowel disease. J Clin Sleep Med 2006;2:409-16.

12 Ranjbaran Z, Keefer L, Farhadi A, et al. Impact of sleep disturbances in inflammatory bowel disease. $J$ Gastroenterol Hepatol 2007;22:1748-53.

13 Katsifaraki M, Nilsen KB, Christensen JO, et al. Sleep duration mediates abdominal and lower-extremity pain after night work in nurses. Int Arch Occup Environ Health 2019;92:1-8.

14 Tang NKY, Goodchild CE, Sanborn AN, et al. Deciphering the temporal link between pain and sleep in a heterogeneous chronic pain patient sample: a multilevel daily process study. Sleep 2012;35:675-87.

15 Alsaadi SM, McAuley JH, Hush JM, et al. The bidirectional relationship between pain intensity and sleep disturbance/quality in patients with low back pain. Clin J Pain 2014;30:755-65.

16 Carney CE, Buysse DJ, Ancoli-Israel S, et al. The consensus sleep diary: standardizing prospective sleep self-monitoring. Sleep 2012;35:287-302.

17 Dallner M. Validation of the general Nordic questionnaire (QPSNordic) for psychological and social factors at work. Nordic Council of Ministers, 2000.

18 Steingrímsdóttir OA, Vøllestad NK, Røe C, et al. Variation in reporting of pain and other subjective health complaints in a working population and limitations of single sample measurements. Pain 2004:110:130-9.

19 Horne JA, Ostberg O. A self-assessment questionnaire to determine morningness-eveningness in human circadian rhythms. Int $J$ Chronobiol 1976;4:97-110.

20 Pallesen S, Bjorvatn B, Nordhus IH, et al. A new scale for measuring insomnia: the Bergen insomnia scale. Percept Mot Skills 2008;107:691-706

21 Johns MW. A new method for measuring daytime sleepiness: the Epworth sleepiness scale. Sleep 1991;14:540-5.

22 Katsifaraki M, Nilsen KB, Wærsted M, et al. The association of sleepiness, insomnia, sleep disturbance and pain: a study amongst shiftworking nurses. Sleep Biol Rhythms 2018;16:133-40.

23 Fitzmaurice GM, Laird NM, Ware JH. Applied longitudinal analysis. 2 edn. Hoboken, New Jersey: Wiley, 2011.

24 Jakobsen GS, Timm AM, Hansen Åse Marie, et al. The association between shift work and treatment-seeking migraine in Denmark. Ergonomics 2017;60:1207-17.

25 Joksimovic L, Starke D, v d Knesebeck O, et al. Perceived work stress, overcommitment, and self-reported musculoskeletal pain: a cross-sectional investigation. Int J Behav Med 2002;9:122-38.

26 Lipscomb JA, Trinkoff AM, Geiger-Brown J, et al. Work-schedule characteristics and reported musculoskeletal disorders of registered nurses. Scand J Work Environ Health 2002;28:394-401.

27 Attarchi M, Raeisi S, Namvar M, et al. Association between shift working and musculoskeletal symptoms among nursing personnel. Iran J Nurs Midwifery Res 2014;19:309.

28 Eriksen W, Bruusgaard D, Knardahl S. Work factors as predictors of intense or disabling low back pain; a prospective study of nurses' aides. Occup Environ Med 2004;61:398-404

29 Zhao I, Bogossian F, Turner C. The effects of shift work and interaction between shift work and overweight/obesity on low back pain in nurses: results from a longitudinal study. J Occup Environ Med 2012;54:820-5.

30 Nojkov B, Rubenstein JH, Chey WD, et al. The impact of rotating shift work on the prevalence of irritable bowel syndrome in nurses. Am J Gastroenterol 2010;105:842-7.

31 Matre D, Nilsen KB, Katsifaraki M, et al. Pain complaints are associated with quick returns and insomnia among Norwegian 
nurses, but do not differ between shift workers and day only workers. Int Arch Occup Environ Health 2020;93:291-9.

32 Bjorvatn B, Pallesen S, Moen BE, et al. Migraine, tension-type headache and medication-overuse headache in a large population of shift working nurses: a cross-sectional study in Norway. BMJ Open 2018;8:e022403.

33 Appel AM, Török E, Jensen MA, et al. The longitudinal association between shift work and headache: results from the Danish PRISME cohort. Int Arch Occup Environ Health 2020;93:601-10.

34 Odegård SS, Sand T, Engstrøm M, et al. The long-term effect of insomnia on primary headaches: a prospective population-based cohort study (HUNT-2 and HUNT-3). Headache 2011:51:570-80.

35 Kosmadopoulos A, Zhou X, Roach GD, et al. No first night shift effect observed following a nocturnal main sleep and a prophylactic $1-\mathrm{H}$ afternoon nap. Chronobiol Int 2016;33:716-20.

36 Vedaa Øystein, Harris A, Bjorvatn B, et al. Systematic review of the relationship between quick returns in rotating shift work and healthrelated outcomes. Ergonomics 2016;59:1-14.

37 Trinkoff AM, Le R, Geiger-Brown J, et al. Longitudinal relationship of work hours, mandatory overtime, and on-call to musculoskeletal problems in nurses. Am J Ind Med 2006;49:964-71. 